\title{
Comparison of local sine wave modelling with harmonic phase analysis for the assessment of circumferential myocardial strain from tagged cardiovascular magnetic resonance images
}

\author{
Christopher A Miller ${ }^{1,2^{*}}$, Alexander Borg ${ }^{1}$, David Clark ${ }^{3}$, Christopher D Steadman ${ }^{4}$, Gerry P McCann ${ }^{4}$, \\ Patrick Clarysse ${ }^{5}$, Pierre Croisille ${ }^{5,6}$, Matthias Schmitt ${ }^{1,2}$
}

From 15th Annual SCMR Scientific Sessions

Orlando, FL, USA. 2-5 February 2012

\section{Background}

Assessment of regional ventricular deformation is more sensitive than ejection fraction (EF) for detecting myocardial dysfunction. We sought to compare a local sinewave modelling (SinMod) method with the more established harmonic phase analysis (HARP) technique, for assessment of Lagrangian left ventricular (LV) peak systolic circumferential strain $(\varepsilon \mathrm{cc})$ from tagged cardiovascular magnetic resonance images, in patients with cardiomyopathies and healthy volunteers. The variability and rapidity of each technique, and the effect of contrast, were also assessed.

\section{Methods}

Sixty participants (15 each with hypertrophic, dilated or ischaemic cardiomyopathy and 15 healthy controls) with a wide range of LV ejection fraction (14-78\%) underwent spatial modulation of magnetization tagging of a mid-ventricular short-axis slice at 1.5 Tesla. Global and segmental peak transmural $\varepsilon c c$ were measured using HARP and SinMod. Repeated measurements were performed on 15 randomly selected scans (25\%) in order to assess observer variability. Tagged images were acquired pre- and post-contrast in 10 additional patients in order to assess the effect of contrast.

\section{Results}

There was a high level of agreement between HARP and SinMod for global $\varepsilon c c$ (mean difference -0.02, 95\% limits

'University Hospital of South Manchester, Manchester, UK

Full list of author information is available at the end of the article of agreement -6.46 to $6.43 \%$, Figure 1). Agreement was much lower for segmental $\varepsilon \mathrm{cc}$, ranging from poor in lateral segments to modest in inferoseptal segments. Both methods showed excellent inter- and intraobserver agreement for global \&cc (intraclass correlation coefficient $>0.75$ ). Inter- and intraobserver agreement for segmental $\varepsilon \mathrm{cc}$ were also excellent with SinMod, and were significantly better than with HARP $(\mathrm{p}<0.0005$, Figure 2 ). SinMod analysis time was significantly shorter than that for HARP $(84 \pm 42$ versus $201 \pm 120$ seconds, $\mathrm{p}=0.02)$. Pre- and post-contrast global and segmental ecc measurements were not significantly different using either technique, although post-contrast measurements showed greater variability with HARP.

\section{Conclusions}

SinMod and HARP-based measurements of global ecc have a high level of agreement. Agreement is substantially lower for measurement of segmental $\varepsilon \mathrm{cc}$. The SinMod method has generally lower observer variability, is faster and is less affected by contrast.

\section{Funding}

Dr Miller was supported by a Doctoral Research Fellowship from the National Institute for Health Research, UK (NIHR-DRF-2010-03-98). Dr Schmitt was supported by Greater Manchester Comprehensive Local Research Network funding. Dr McCann and Dr Steadman received support from the NIHR Leicester Cardiovascular Biomedical Research Unit and additionally, Dr Steadman was funded by the British Heart Foundation (PG/ 07/068/2334). 


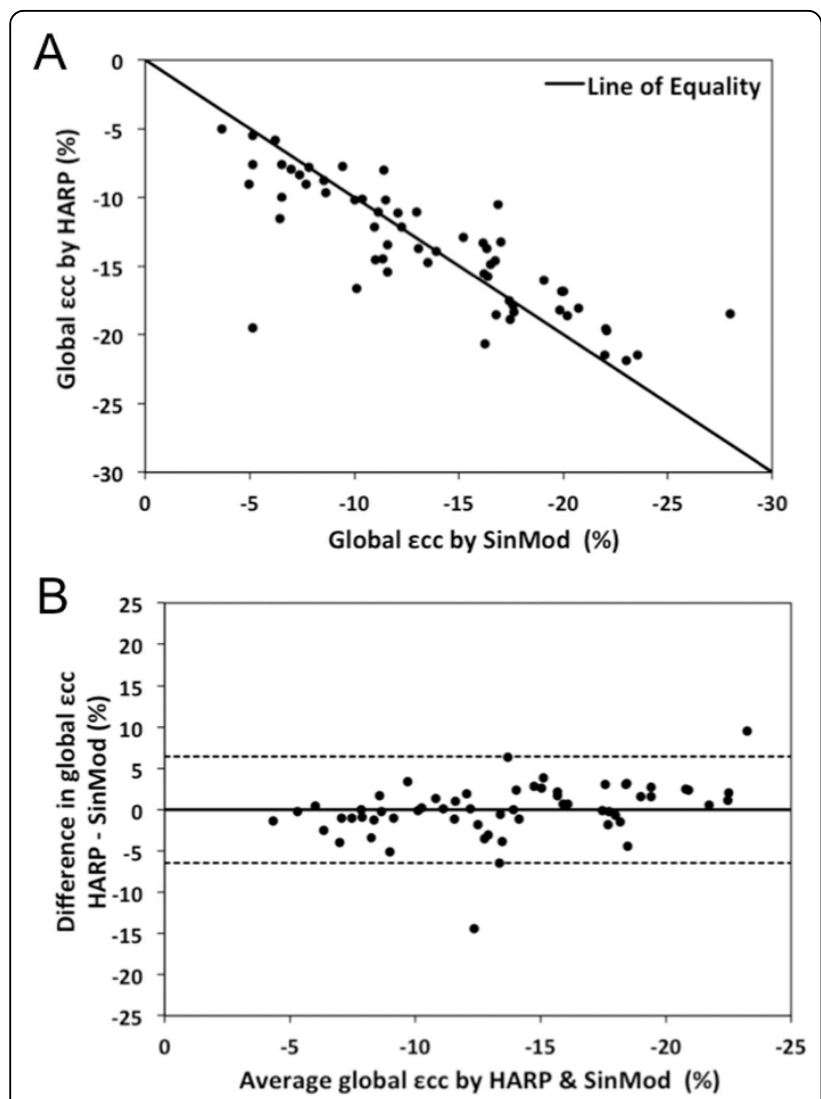

Figure 1 Agreement between local sine-wave modelling (SinMod) and harmonic phase (HARP) analysis methods for measurement of global peak systolic circumferential strain $(\varepsilon \subset C)$. (A) Scatter plot with line of equality; (B) Bland Altman plot.

\section{Author details}

'University Hospital of South Manchester, Manchester, UK. ${ }^{2}$ University of Manchester, Manchester, UK. ${ }^{3}$ Alliance Medical, Wythenshawe CMR Unit, Manchester, UK. ${ }^{4}$ NIHR Leicester Cardiovascular Biomedical Research Unit, Leicester, UK. ${ }^{5}$ Université de Lyon, Lyon, France. ${ }^{6}$ Université Jean Monnet, Saint-Etienne, France.

Published: 1 February 2012

doi:10.1186/1532-429X-14-S1-P277

Cite this article as: Miller et al:: Comparison of local sine wave modelling with harmonic phase analysis for the assessment of circumferential myocardial strain from tagged cardiovascular magnetic resonance images. Journal of Cardiovascular Magnetic Resonance 201214 (Suppl 1):P277.

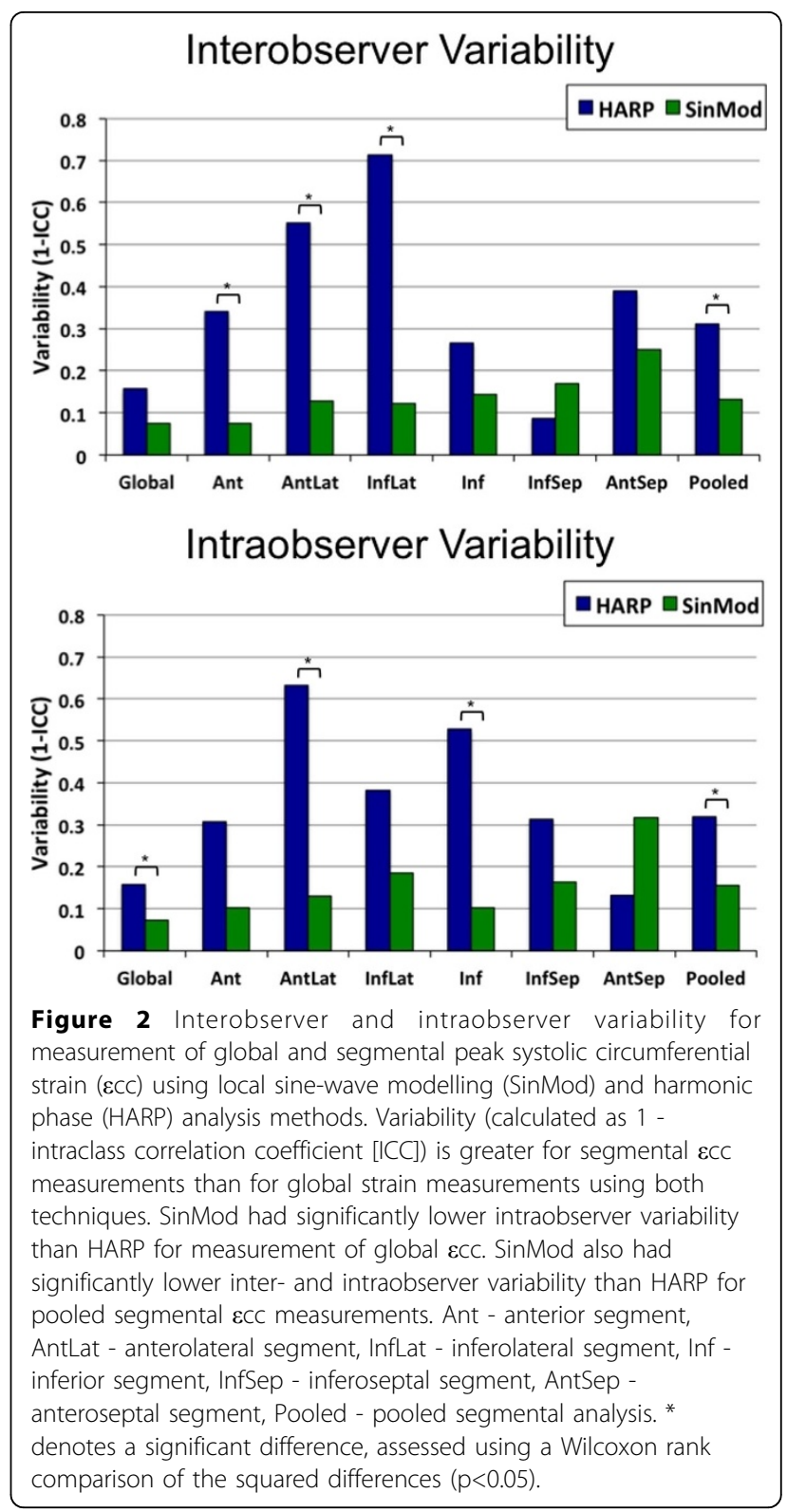

\section{Submit your next manuscript to BioMed Central} and take full advantage of:

- Convenient online submission

- Thorough peer review

- No space constraints or color figure charges

- Immediate publication on acceptance

- Inclusion in PubMed, CAS, Scopus and Google Scholar

- Research which is freely available for redistribution

Submit your manuscript at www.biomedcentral.com/submit 